\title{
QSAR Optimization of Benzofuran and Benzothiophene Sulfono Biphenyl as Potent PTPase-1B Inhibitors
}

\author{
Darpan Kaushik ${ }^{1}$, Suroor A. Khan ${ }^{1}$, Ozair Alam ${ }^{1}$, Geeta Chawla ${ }^{1}$ \\ and Satish G. Kashedikar² \\ ${ }^{1}$ F/O Pharmacy, Jamia Hamdard University, New Delhi-110062, India \\ ${ }^{2}$ Shri G.S. Institute of Technology and Sciences, Indore-452003, M.P., India
}

\begin{abstract}
Insulin resistance is associated with a defect in protein tyrosine phosphorylation in the insulin signal transduction cascade. Protein tyrosine phosphatase (PTPase) enzyme dephosphorylates the active form of insulin receptor and thus attenuates its tyrosine kinase activity, therefore the need of potent PTPase inhibitor is there with that intention the Quantitative structure-activity relationship QSAR was performed. QSAR has been established on a series of compounds of novel sulfono biphenyl analogs using SYSTAT (Version 7.0) software, for their PTPase-1B inhibitor activity, in order to understand the essential structural requirement for binding with the receptor. Among several 2D QSAR models, one for a series was selected on the basis of high correlation coefficient, least standard deviation, \& high value of significance for maximum no. of subject was considered. The interpreted data signify the essentiality of Benzofuran ring in the designing of the new PTPase -1B inhibitors and any substitution on the biphenyl and sulfonyl phenyl is going to decrease its activity.
\end{abstract}

Key words: QSAR, PTPase-1B inhibitor, Sulfono biphenyl analog.

\section{INTRODUCTION}

Diabetes has recognized as a genetic disorder, in which glucose metabolism is altered. The ability of insulin to bring about such a dramatic reversal in the symptoms of diabetes, with a return to a 'near normal' life expectancy, led the medical community to conclude that the problems of etiology and treatment had been resolved, but these conclusions were premature, whereas insulin does return control of blood glucose level and does offset the development of ketoacidosis, it doesn't appear to rectify all of the metabolic defects identifiable in the diabetic. $^{1}$

Correspondence to: Darpan Kaushik

E-mail: darpkaush@yahoo.com

Dhaka Univ. J. Pharm. Sci. 6(2): 77-80, 2007 (December)
It is thus evident that insulin therapy, as currently is not a panacea for diabetes mellitus. This realization has promoted to a great deal of research toward the development of more effective way of treating the disease and has led to the discovery of various hypoglycemic agents e.g. Sulphonylurea, Biguanide, recently developed glitazones. Though recently developed glitazones are also monitored for the hepatotoxic effect. Thus there is a need for the better and safer hypoglycemic agent.

It is now well established that insulin resistance can result from a defect in the insulin receptor signaling system at a site post binding of insulin to its receptor. $^{2}$ Insulin resistance is associated with a defect in protein tyrosine phosphorylation in the insulin signal transduction cascade. PTPase enzyme 
dephosphorylates the active form of insulin receptor and thus attenuates its tyrosine kinase activity. ${ }^{3}$

Insulin resistance is thus one of the obstacles which we confront while undergoing therapy for diabetes mellitus. A number of PTPase inhibitors has been designed and studied to overcome this problem, to gain insight into the structural and molecular requirements influencing the PTPase-1B inhibition activity, we here in describe the QSAR analysis of a set of structurally different compounds of PTPase inhibitors, for which it is conceivable to make assumption that they interact with the enzyme.

\section{MATERIALS AND METHODS}

Malamas et al. $^{4}$ reported seven series of compounds based on Benzofuran/Benzothiophene biphenyl moiety. We performed the QSAR analysis of sulfono biphenyls which was sub-divided in two series (Tables $1 \& 2$ ) having $10 \& 5$ compounds (Structure $1 \& 2$ ) respectively. 2D QSAR study were carried out in the following steps:

Table 1. Chemical and Biological Data of sulfono biphenyl Analogs [Structure 1]

\begin{tabular}{ccccccc}
\hline Compd & $\mathrm{R}^{1}$ & $\mathrm{R}^{2}$ & $\mathrm{R}^{3}$ & $\mathrm{R}^{4}$ & $\mathrm{X}$ & $\mathrm{IC}_{50}$ \\
\hline 1 & $\mathrm{H}$ & $\mathrm{COOH}$ & $\mathrm{H}$ & $\mathrm{H}$ & $\mathrm{O}$ & 0.075 \\
2 & $\mathrm{COOH}$ & $\mathrm{H}$ & $\mathrm{H}$ & $\mathrm{H}$ & $\mathrm{O}$ & 0.106 \\
3 & $\mathrm{OH}$ & $\mathrm{COOH}$ & $\mathrm{H}$ & $\mathrm{H}$ & $\mathrm{O}$ & 0.039 \\
4 & $\mathrm{COOH}$ & $\mathrm{OH}$ & $\mathrm{H}$ & $\mathrm{H}$ & $\mathrm{O}$ & 0.026 \\
5 & $\mathrm{OH}$ & $\mathrm{COOH}$ & $\mathrm{CH}_{3}$ & $\mathrm{CH}_{3}$ & $\mathrm{O}$ & 0.034 \\
6 & $\mathrm{OH}$ & $\mathrm{COOH}$ & $\mathrm{NO}_{2}$ & $\mathrm{H}$ & $\mathrm{O}$ & 0.029 \\
7 & $\mathrm{OH}$ & $\mathrm{COOH}$ & $\mathrm{Cyclopentyl}_{2}$ & $\mathrm{H}$ & $\mathrm{O}$ & 0.028 \\
8 & $\mathrm{OH}$ & $\mathrm{COOH}$ & $\mathrm{H}$ & $\mathrm{H}$ & $\mathrm{S}$ & 0.028 \\
9 & $\mathrm{OH}$ & $\mathrm{COOH}$ & $\mathrm{Br}$ & $\mathrm{H}$ & $\mathrm{S}$ & 0.024 \\
10 & $\mathrm{OH}$ & $\mathrm{COOH}$ & $\mathrm{Br}$ & $\mathrm{Br}$ & $\mathrm{S}$ & 0.030 \\
\hline
\end{tabular}

Table 2. Chemical and Biological Data of Sulfono biphenyl Analogs [Structure 2]

\begin{tabular}{|c|c|c|c|c|c|c|}
\hline Comp & $\mathrm{R}^{1}$ & $\mathrm{R}^{2}$ & $\mathrm{R}^{3}$ & $\mathrm{R}^{4}$ & $\mathrm{R}^{5}$ & $\mathrm{IC}_{50}$ \\
\hline 1 & $\mathrm{OH}$ & $\mathrm{COOH}$ & $\mathrm{H}$ & $\mathrm{H}$ & & 0.032 \\
\hline 2 & $\mathrm{OH}$ & $\mathrm{COOH}$ & Cyclopentyl & $\mathrm{H}$ & & 0.040 \\
\hline 3 & $\mathrm{OH}$ & $\mathrm{COOH}$ & $\mathrm{H}$ & $\mathrm{H}$ & & 0.354 \\
\hline 4 & OAc & $\mathrm{COOH}$ & $\mathrm{H}$ & $\mathrm{H}$ & & 1.16 \\
\hline 5 & $\mathrm{OH}$ & $\mathrm{COOH}$ & $\mathrm{NO}_{2}$ & $\mathrm{H}$ & & 0.178 \\
\hline
\end{tabular}

\section{A. Calculations of Physico-chemical constants}

from literature ${ }^{5}$. The values for the physicochemical constants for various substituents were determined from the literature. The determined parameters for series VI include, Hansch constant $(\pi)$, Molar Refractivity $(\eta)$, Sigma/Hammet constant $(\sigma)$, Field effect (f) and Indicator value (I). 
The substituent in the Structure 1:

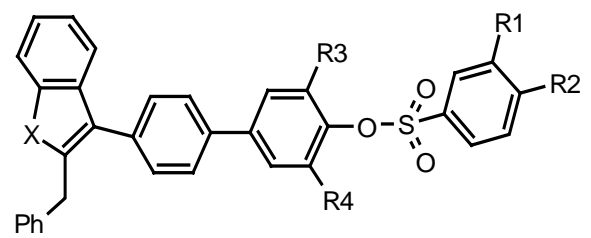

For Series VI: $I^{1}, I^{2}, I^{4}, I_{X}, \pi R^{3}, \sigma R^{3}, \eta R^{3}, \mathrm{fR}^{3}$

$\mathrm{IR}^{1}$ (Indicator parameter of $\mathrm{R}^{1}$ substituent)

$\mathrm{IR}^{1}=1$, where $-\mathrm{OH}$ present at $\mathrm{R}^{1}$ position, otherwise, considered as 0 .

$\mathrm{IR}^{2}$ (Indicator parameter for $\mathrm{R}^{2}$ substituent).

$\mathrm{IR}^{2}=1$, where $-\mathrm{COOH}$ is at $\mathrm{R}^{2}$ position, otherwise, rest other as 0 .

$\mathrm{IR}^{4}$ (Indicator parameter for $\mathrm{R}^{4}$ substituent).

$\mathrm{IR}^{3}=1$, where $\mathrm{H}$ is at $\mathrm{R}^{3}$ position, otherwise, other substituent considered as $0 . \pi R^{3}, \sigma R^{3}, \eta R^{3}, \mathrm{fR}^{3}$ are the physicochemical parameter for substitution $\mathrm{R}^{3}$.

$\mathrm{I}_{\mathrm{X}}$ (Indicator variable for $\mathrm{X}$ position)

$\mathrm{I}_{\mathrm{X}}=1$, when $\mathrm{O}$ is present at the $\mathrm{X}$ position i.e, for Benzofuran ring and for Benzothiophene ring it is 0 .

The substituents in Structure II are as follows:

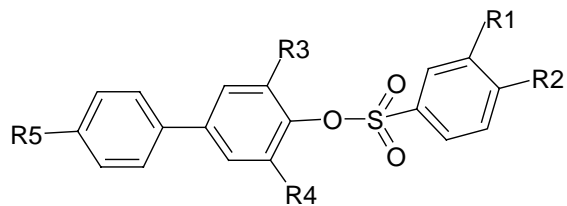

For Series VII: $I^{1}, I^{2}, \pi R^{3}, \sigma R^{3}, \eta R^{3}, I^{4}, I^{5}$, $\pi \mathrm{IR}^{5}, \sigma \mathrm{IR}^{5}, \eta \mathrm{R}^{5}$

$\mathrm{IR}^{1}$ (Indicator parameter for $\mathrm{R}^{1}$ substituent)

$I^{1}=1$, where -OH present at $R^{1}$ position, otherwise 0 .

$\mathrm{IR}^{2}$ (Indicator parameter for $\mathrm{R}^{2}$ substituent)

$\mathrm{IR}^{2}=1$, where $\mathrm{COOH}$ is at $\mathrm{R}^{2}$ position, other substituent considered as 0 .

$\pi R^{3}, \sigma R^{3}, \eta R^{3}$ are the physiochemical parameter of $\mathrm{R}^{3}$ substituent.

$\mathrm{IR}^{4}$ (Indicator parameter for $\mathrm{R}^{4}$ substituent)

$\mathrm{IR}^{4}=1$, where $\mathrm{H}$ present at $\mathrm{R}^{4}$ position, otherwise considered as 0 .

$\mathrm{IR}^{5}=1$, when Benzofuran ring present at $\mathrm{R}^{5}$, rest other considered as 0 .

$\pi \mathrm{IR}^{5}, \quad \sigma \mathrm{IR}^{5}, \quad \eta \mathrm{IR}^{5}$ are the physiochemical parameter of $\mathrm{R}^{5}$ substituent.

\section{B. Determination of the Correlation matrix.}

The correlation matrix for series VI \& VII was determined separately using the program 'SYSTAT' ${ }^{\mathbf{6}}$ (version 7.0). The most significant parameters for PTPase inhibiting activity were chosen on the basis of their correlation ship \& Interco relationship (Tables $3 \& 4$ ) respectively.

Table 3 Correlation Matrix [Structure 1]

\begin{tabular}{llllllllll}
\hline & $\operatorname{LogIC} C_{50}$ & $\mathrm{IR}^{1}$ & $\mathrm{IR}^{2}$ & $\mathrm{IR}^{4}$ & $\mathrm{I}_{\mathrm{X}}$ & $\pi \mathrm{R}^{3}$ & $\eta \mathrm{R}^{3}$ & $\sigma \mathrm{R}^{3}$ & $\mathrm{fR}^{3}$ \\
\hline $\operatorname{LogIC}_{50}$ & 1.000 & & & & & & & & \\
$\mathrm{IR}^{1}$ & -0.666 & 1.000 & & & & & & & \\
$\mathrm{IR}^{2}$ & -0.381 & 0.764 & 1.000 & & & & & & \\
$\mathrm{IR}^{4}$ & 0.150 & -0.327 & -0.250 & 1.000 & & & & & \\
$\mathrm{I}$ & 0.420 & -0.429 & -0.327 & 0.218 & 1.000 & & & & \\
$\pi \mathrm{R}^{3}$ & -0.343 & 0.395 & 0.302 & -0.220 & -0.156 & 1.000 & & & \\
$\eta \mathrm{R}^{3}$ & -0.444 & 0.519 & 0.397 & -0.150 & -0.082 & 0.900 & 1.000 & & \\
$\sigma \mathrm{R}^{3}$ & -0.238 & 0.244 & 0.186 & 0.128 & -0.146 & -0.311 & 0.094 & 1.000 & \\
$\mathrm{fR}^{3}$ & -0.350 & 0.374 & 0.286 & -0.111 & -0.388 & -0.112 & 0.219 & 0.926 & 1.000 \\
\hline
\end{tabular}

C. Multiple regression analysis. It was performed by using the program 'SYSTAT' (version 7.0) for PTPase inhibiting activity of sulfono biphenyls, i.e. $-\operatorname{logIC} \mathrm{C}_{50}$ considered as dependent variable and $I R^{1}, I R^{2}, I R^{4}, I_{X}, \pi R^{3}, \sigma R^{3}, \eta R^{3}, R^{3} \&$ $\mathrm{IR}^{1}, \mathrm{IR}^{2}, \pi \mathrm{R}^{3}, \sigma \mathrm{R}^{3}, \eta \mathrm{R}^{3}, \mathrm{IR}^{4}, \mathrm{IR}^{5}, \pi \mathrm{IR}^{5}, \sigma \mathrm{IR}^{5}, \eta \mathrm{R}^{5}$ were selected as the independent variables separately for series VI\& VII. 


\section{RESULTS AND DISCUSSION}

The significant equation obtained for series VI \& VII are equation $1,2 \& 3$ respectively:

$-\log \mathrm{IC}_{50}=-0.474( \pm 0.060) \mathrm{IR}^{1}-1.050( \pm 0.053)$

$\mathrm{n}=9, \mathrm{r}=0.949, \mathrm{~s}=0.074, \mathrm{~F}=63.210$

$-\log \mathrm{IC}_{50}=-0.150( \pm 0.095) \mathrm{IR}^{2}-0.398( \pm 0.072) \mathrm{IR}^{1}-$ $0.975( \pm 0.068)$

$\mathrm{n}=9, \mathrm{r}=0.964, \mathrm{~s}=0.068, \mathrm{~F}=39.512$
$-\operatorname{logIC} C_{50}=1.054( \pm 0.025) \mathrm{IR}^{5}-0.051( \pm 0.001) \eta \mathrm{R}^{3}-$ 0.505( \pm 0.025$) \mathrm{IR}^{1}-0.937( \pm 0.031)$

$\mathrm{n}=5, \mathrm{r}=1, \mathrm{~s}=0.019, \mathrm{~F}=1532.092$

In equation $1 \& 2$, only 9 subjects are considered because subject 4 considered as an outlier as its residual value exceeds the leverage value. The data showed the overall significance level better than $99.95 \%$ because it exceeds the tabulated value of $\mathrm{F}$.

Table 4. Correlation Matrix [Structure 2]

\begin{tabular}{|c|c|c|c|c|c|c|c|c|c|c|c|}
\hline & $\log \mathrm{IC}_{50}$ & $\mathrm{IR}^{1}$ & $\mathrm{IR}^{2}$ & $\pi \mathrm{R}^{3}$ & $\eta \mathrm{R}^{3}$ & $\sigma \mathrm{R}^{3}$ & $\mathrm{IR}^{4}$ & $\mathrm{IR}^{5}$ & $\pi \mathrm{IR}^{5}$ & $\eta \mathrm{R}^{5}$ & $\sigma \mathrm{IR}^{5}$ \\
\hline $\log \mathrm{IC}_{50}$ & 1.000 & & & & & & & & & & \\
\hline $\mathrm{IR}^{1}$ & -0.744 & 1.000 & & & & & & & & & \\
\hline $\mathrm{IR}^{2}$ & & & & & & & & & & & \\
\hline$\pi \mathrm{R}^{3}$ & 0.114 & 0.206 & & 1.000 & & & & & & & \\
\hline$\eta \mathrm{R}^{3}$ & -0.504 & 0.345 & & -0.038 & 1.000 & & & & & & \\
\hline$\sigma \mathrm{R}^{3}$ & 0.114 & 0.206 & & 0.100 & -0.038 & 1.000 & & & & & \\
\hline $\mathrm{IR}^{4}$ & & & & & & & & & & & \\
\hline $\mathrm{IR}^{5}$ & 0.589 & -0.250 & & 0.206 & 0.345 & 0.206 & & 1.000 & & & \\
\hline$\pi \mathrm{IR}^{5}$ & -0.374 & 0.408 & & 0.504 & 0.844 & 0.504 & & 0.408 & 1.000 & & \\
\hline$\eta R^{5}$ & -0.353 & 0.396 & & 0.504 & 0.844 & 0.504 & & 0.432 & 1.000 & 1.000 & \\
\hline$\sigma \mathrm{IR}^{5}$ & -0.374 & 0.408 & & 0.504 & 0.844 & 0.504 & & 0.408 & 1.000 & 1.000 & 1.000 \\
\hline
\end{tabular}

From this data analysis, we can conclude that for series VI for both the equation any substituent at $\mathrm{R}^{1}$ $\& R^{2}$ position is going to decrease the activity of compound similarly for series VII, although the result are not significant in term as number of variable for the number of subject considered is more than the specified limit of 1: 5, therefore the equation doesn't find any significance but then too equation gives an impression that any substitution at $\mathrm{R}^{1}$ or $\mathrm{R}^{3}$ is going to decrease its activity but the major outcomes proves the essentiality of the presence of Benzofuran ring at $\mathrm{R}^{5}$ position is going to make the significant contribution in binding with the receptor and thus this information can be further be utilized in designing of the PTPase-1B inhibitors.

Finally, it can be concluded that the work presented here will play an important role in understanding the relationship of physicochemical parameters with structure and biological activity of the PTPase 1B inhibitor and will help in choosing the suitable substituent for getting the active compound with maximum potency.

\section{ACKNOWLEDGEMENT}

The author's thanks the Director, CDRI, Lucknow \& Dr. A.K Saxena for providing necessary facilities. Darpan Kaushik is grateful to UGC for providing financial assistantship during this project.

\section{REFERENCES}

1. Foye, W.O. 1989. Principles of Medicinal Chemistry, Varghese Publishing House, Bombay, $3^{\text {rd }}$ edition, pp. 531.

2. Haring, H.U. 1991. The Insulin receptor: Signaling mechanism and contribution to the pathogenesis of insulin resistance. Diabetologia, 34, 848-861.

3. Goldstein, B.J. 1992. Protein- Tyrosine Phosphatases and the regulation of Insulin action. J. Cell. Biochem. 31, 33-42.

4. Malamas, M.S., Sredy, J., Moxham, C., Katz, A., W.Xu, McDevitt, R., Adebayo, F.O., Sawicki, D.R., Seestaller, L., Sullivan, D. and Taylor; J.R. 2000. Novel Benzofuran and Benzothiophene Biphenyls as inhibitors of Protein Tyrosine Phosphatase 1B with Antihyperglycemics properties. J. Med. Chem. 43, 1293-1310.

5. Hansch, C and Leo, A. 1979. Substituent constants for correlation analysis in chemistry and biology, John Wiley and Sons, New York, 48.

6. Systat, (version 7.0). S.P.S.S., Inc., 944, North Michigan Avenue, Chicago, IL 60611.U.S. 
